\title{
Desenvolvimento, neodesenvolvimentismo e impactos sobre o trabalho na Amazônia brasileira
}

\section{Development, neodevelopmentism and work impacts on brazilian Amazon}

Adriana de Azevedo Mathis - Pós-doutorado pela Universidade Livre de Berlin, Alemanha. Professora e pesquisadora do Programa de Pós-graduação em Serviço Social da Faculdade de Serviço Social/FASS/ICSA/UFPA. E-mail: drika.azevedo@hotmail.com.

Maria Antônia Cardoso do Nascimento - Pós-Doutorado em Políticas Sociais pela Universidade Federal de Pernambuco/UFPE. Professora e pesquisadora do Programa de Pós-graduação em Serviço Social da Faculdade de Serviço Social/FASS/ICSA/UFPA. E-mail:mariaant@ufpa.br.

Nádia Socorro Fialho Nascimento - Pós-Doutorado em Serviço Social pela Universidade Federal de Pernambuco/UFPE. Professora e pesquisadora do Programa de Pósgraduação em Serviço Social da Faculdade de Serviço Social/FASS/ICSA/UFPA. E-mail: fialho@ufpa.br.

Vera Lúcia Batista Gomes - Pós-doutorado em Serviço Social. Professora e pesquisadora do Programa de Pós-graduação em Serviço Social da Faculdade de Serviço Social/FASS/ ICSA/UFPA. E-mail: veragomesbelem@hotmail.com.

\section{Resumo}

Este artigo aborda os impactos socioeconômicos dos processos de desenvolvimento sobre o trabalho na Amazônia brasileira. Tem como objetivo refletir sobre a realidade social dos trabalhadores que residem nos municípios afetados por projetos econômicos agropecuários, minerometalúrgicos e energéticos. Tomando como lócus o estado do Pará a partir de estudos bibliográficos, documentais e pesquisas de campo, os resultados indicam que a perspectiva desenvolvimentista, em sua versão clássica e/ ou contemporânea, tem acirrado as desigualdades sociais e (re)produzido expressões da "questão social" na região.

\section{Palavras-chave}

Desenvolvimento. Neo-Desenvolvimentismo. Trabalho.

\begin{abstract}
This article discusses the socioeconomic impacts of development proposals and, more recently, neo-developmentalism in the context of the work in Brazilian Amazon. It aims to reflect about the reality of people that work and live in the cities affected by economic projects involving agriculture, energy, mining and metallurgical. Taking the state of Pará as the focus of data analysis, bibliographic studies, and field research, the results indicate that a development perspective, in its classical and/ or contemporary version, has strained social inequalities and (re)produced expressions of "social issues" in the region.
\end{abstract}

\section{Keywords}

Development. Neo-Developmentism. Work. 


\section{INTRODUÇÃO}

O tema do desenvolvimento e do neodesenvolvimentismo tem sido recolocado como demanda econômica, política, teórica e prática nos diversos espaços de discussão que problematizam a atual conjuntura mundial. No Brasil, na primeira década dos anos 2000, as análises macroestruturais destacaram a sua relevância e a potencialidade econômica como um dos países de liderança na dinâmica econômica e política global a partir da ampliação do Produto Interno Bruto - PIB ${ }^{1}$. O Departamento Intersindical de Estatística e Estudos Socioeconômicos - DIEESE registra que o país, em 2010, teve um crescimento de cerca de 7,5\% do emprego formal, além da ampliação da renda e uma significativa redução da pobreza absoluta $^{2}$. Estas alterações, combinadas com uma política externa fortalecida, possibilitaram o ingresso do país no contexto de desenvolvimento globalizado de modo mais "autônomo" e estratégico embora, a despeito desse crescimento econômico, o Brasil permaneça como um dos países mais desiguais na América Latina e no mundo, apresentando um índice de Gini de apenas 0,56 (PNUD, 2010). A desigualdade social, herança do processo colonial, agrava esta situação para os brasileiros que residem distante dos grandes centros urbanos da Região Amazônica, habitados por significativo contingente de populações tradicionais como índios e quilombolas e trabalhadores rurais migrantes.

Para desenvolver a reflexão sobre os impactos sociais na realidade da Amazônia brasileira a partir do modelo de desenvolvimento e/ou desenvolvimentismo; a primeira seção desse texto expõe uma síntese do debate teórico atual acerca do ressurgimento do tema do desenvolvimento na década de 1990. A segunda seção salienta os rebatimentos da retórica do desenvolvimento na realidade rural do estado do Pará e, ao final, são evidenciadas, reflexões críticas obtidas a partir das pesquisas de campo realizadas pelas autoras em múltiplos espaços de atuação.

\section{DESENVOLVIMENTO E NEODESENVOLVIMENTISMO NA AMÉRICA LATINA}

Segundo Sampaio Jr. (2012), o brutal desequilíbrio na correlação de forças entre capital e trabalho tornou-se premissa fundamental no continente latinoamericano e o novo contexto histórico tornou-se determinante para uma revisão radical das bases teóricas do estruturalismo desenvolvimentista, transformando

\footnotetext{
A crise vivenciada pelo país desde 2014 tende a colocar em questão os ganhos do período mencionado.

2 Segundo o DIESSE/2011, considera-se em pobreza extrema pessoas com renda familiar per capita até $1 \frac{1}{4}$ do salário mínimo.
} 
a problemática do desenvolvimento em problemática do desenvolvimento capitalista. Em consequência, ocorreu o esgotamento do nacionaldesenvolvimentismo com a introdução do projeto neoliberal e a emergência do regime de acumulação financeirizado, mudando, assim, o contexto político sulamericano no final dos anos 1990 e início do século XXI.

O neoliberalismo tem uma longa história na América Latina, que se inicia nos anos 1970, com o golpe militar do general Augusto Pinochet que derrubou o governo de Salvador Allende e liquidou a vida democrática do socialismo chileno. Apoiado pelos Estados Unidos, pelas grandes multinacionais e pelos setores mais reacionários da sociedade chilena, o golpe armado pavimentou o caminho para os tecnocratas importados diretamente de Chicago, então comandados por Milton Friedman, implementarem o receituário típico do neoliberalismo.

Nos anos 1980, com a vitória dos conservadores da Inglaterra, nos Estados Unidos e na Alemanha, o neoliberalismo ressurge sob uma nova roupagem hegemônica, sem, contudo, descartar medidas coercitivas de repressão às resistências populares. Nesse período, o objetivo do neoliberalismo era se apresentar como alternativa ao esgotamento do modelo de industrialização por substituição de importações e da ideologia desenvolvimentista, prometendo acabar com a crise da dívida externa e a alta inflação (CASTELO, 2010).

No entanto, o projeto de restauração do capital, a partir de meados da década de 1990, passou a vivenciar uma crise conjuntural em decorrência “das crises financeiras do México, Tigres Asiáticos, Rússia, Brasil e Argentina, bem como das reações das classes subalternas, como o levante zapatista e os movimentos globais antisistêmicos" (CASTELO, 2012: 47). Em face dessa crise, que ameaçava parte da hegemonia neoliberal, em nível mundial, ideólogos das diversas instituições começaram um processo de revisão dos principais pontos do referido projeto que constam no Consenso de Washington.

Essa revisão, ainda segundo o referido autor, pode ser chamada de socialliberalismo cujas principais medidas direcionavam-se para a tentativa de acoplar uma agenda social ao projeto neoliberal, promovendo a conciliação de medidas de estímulo a intervenções pontuais do Estado e do chamado Terceiro Setor nas principais expressões da questão social, reconhecendo as falhas de mercado, de forma que não atinja os fundamentos do mercado no capitalismo.

Apresentando-se como uma terceira via tanto ao projeto neoliberal quanto para o socialismo, o social-liberalismo caracteriza-se por um sincretismo entre o mercado e o Estado conduzido por uma ideologia de promoção do bem-estar social. Se utilizando de um pensamento ortodoxo neoliberal, os estruturalistas passaram a defender um modelo de desenvolvimento em que o Estado possa 
desempenhar um papel ativo para o mercado com empenho para facilitar a entrada de capital externo dirigida para o financiamento do investimento produtivo.

Este movimento marca uma inflexão do pensamento hegemônico, envernizado por uma ética de esquerda com palavras de ordem como justiça social, solidariedade, filantropia e voluntariado com debates sobre equidade, capital humano, vulnerabilidade, exclusão social, ativismo ético e virtuoso (comunidades dotadas do capital social), funcionalidade do Terceiro Setor, sustentabilidade do meio ambiente e consciência social das empresas.

Diante do fracasso da postura onipresente do mercado sob orientação neoliberal, nas duas últimas décadas do século XX são reelaboradas novas estratégias de dominação capitalista sem prejuízo do objetivo principal: expansão do capital com hegemonia política. Nesta perspectiva, a retomada do discurso do desenvolvimento se pauta na premissa de que está em curso uma retomada das reformas liberais, uma nova configuração do Estado e, por conseguinte, uma reorientação das políticas sociais baseadas em programas focalizados dirigidos exclusivamente para a população pobre.

Este fato pode ser explicado pela total incompatibilidade presente no mecanismo para o enfrentamento da relação contraditória posta entre capital e trabalho, pois se trata de: "uma série de desequilíbrios macroeconômicos e sociais na América Latina manifestada na degradação do mundo do trabalho expressa no desemprego estrutural, na precarização das relações de trabalhistas, na redução dos direitos sociais e no pauperismo" (CASTELO, 2010: 22).

Diante dessa situação, a solução para os problemas suscitados pelas políticas neoliberais, segundo a racionalidade burguesa, passa pela intensificação da intervenção da ação estatal, a fim de dar sustentabilidade para a liberdade do mercado e de intervenção em políticas de "enfrentamento" à pobreza. Esta racionalidade é a mesma da constituição dos mercados, conforme assinala Polanyi (1980: 146): "A constituição dos mercados, longe de abolir a necessidade de controle, regulamentação e intervenção, incrementou enormemente o seu alcance. Os administradores tinham que estar sempre alerta para garantir o funcionamento livre do sistema".

Constata-se, assim, que as propostas emanadas do chamado Pós-Consenso de Washington mantiveram os princípios do primeiro Consenso, complementando com medidas que reforçam a capacidade institucional do Estado com ênfase nos princípios político-ideológicos de maior intervenção nas expressões da "questão social" nos países periféricos. Assim, para Fiori (2009), a adoção das medidas do Pós-Consenso significou uma mudança de política imposta pela força dos fatos e não por uma nova convicção teórica ou ideológica dos governantes mundiais. 
Dessa forma, os ajustes efetuados nas reformas do Consenso de Washington mantiveram a disciplina macroeconômica, as privatizações, a desregulação, a abertura comercial e financeira, objetivando eliminar todo tipo de barreiras ou discriminações contra os capitais, fortalecendo o entorno legal e regulatório por meio de medidas de desregulação do mercado de trabalho e melhoria das regulações no que tange aos investimentos privados em infraestrutura e serviços sociais (WILLIAMSON; KUCZYNSKI, 2004).

A complementaridade dessas reformas, particularmente, na América Latina, ocorre com medidas que prevêem, no plano ideológico, a melhoria da qualidade do setor público, a parceria público e privado, a sustentabilidade do meio ambiente, dos investimentos em capital humano e, principalmente, que dê maior ênfase ao combate à pobreza e à distribuição de renda.

Nessa perspectiva, foi criada a chamada terceira via de desenvolvimento que se inicia na segunda fase do neoliberalismo (social-liberalismo), caracterizada por um sincretismo entre o mercado e o Estado conduzido por uma ideologia de promoção do bem-estar social. Constata-se, então, que a aliança dos neodesenvolvimentistas com o bloco social-liberal não se dá apenas no aspecto político, pois ambos compartilham da ideologia burguesa que compreende de forma limitada e superficial a dinâmica da acumulação capitalista e seus nexos com o subdesenvolvimento e a dependência do Brasil aos centros capitalistas. De igual modo, não questionam "as dimensões nacionais e internacionais das lutas de classe, a natureza do Estado classista e das ideologias, o imperialismo das corporações multinacionais e dos Estados centrais e o caráter exploratório e iníquo da acumulação de capital" (CASTELO, 2010: 207).

Dessa forma, o neodesenvolvimentismo, ao adotar posições centristas moderadas que em quase nada lembram o velho desenvolvimentismo latinoamericano, coloca em discussão projetos nacionais de crescimento econômico combinado a uma melhora substancial nos padrões distributivos da América Latina: "A consecução desse objetivo passa, necessariamente, por um determinado padrão de intervenção do Estado na economia e na 'questão social', principalmente, no tocante à redução da incerteza inerente às economias capitalistas periféricas a influência das ideias keynesianas" (CASTELO, 2010: 208).

\section{O NEODESENVOLVIMENTISMO E A PARTICULARIDADE BRASILEIRA}

No Brasil, as "reformas" com base nas ideias neodesenvolvimentistas tiveram o seu início, oficialmente, no governo do presidente Fernando Henrique 
Cardoso - FHC, através do projeto de Emenda Constitucional n. ${ }^{\circ} 173$ cujo principal responsável foi o então ministro da Administração e Reforma do Estado (extinto MARE) Luiz Carlos Bresser Pereira. A proposta apresenta a necessidade de se "reformar" o Estado brasileiro e torná-lo um Estado SocialLiberal: social porque continuará a proteger os direitos sociais e a promover o desenvolvimento econômico; liberal porque o fará usando mais os controles de mercado e menos os controles administrativos, porque realizará os seus serviços sociais e científicos, principalmente, por meio de organizações públicas não estatais competitivas, porque tornará os mercados de trabalho mais flexíveis, porque promoverá a capacitação de recursos humanos e de suas empresas para a inovação e a competição internacional

Tais propostas ganham materialidade institucional por meio de políticas sociais assistencialistas e focalizadas de transferência de renda, programas de economia solidária e de "empoderamento" dos indivíduos e comunidades e de medidas regulatórias do Estado diante das falhas do mercado. Essas políticas aparecem descritas como orientações oficiais no Relatório da Força-Tarefa sobre Políticas de Emprego ${ }^{3}$. De acordo com este Relatório, oriundo do Ministério do Trabalho e Emprego (MTE, 1998: 20-21), as políticas de trabalho emprego e renda devem: i) assegurar a estabilidade econômica; ii) dar continuidade às mudanças institucionais, com o objetivo de gerar poupança e atrair novos investimento; iii) promover ações geradoras de emprego e renda através de políticas ativas, com ênfase no apoio creditício e técnico às pequenas empresas e trabalhadores autônomos; iv) investir em capital humano e na formação profissional da força de trabalho; e, v) reformar as instituições que regulam o funcionamento do mercado de trabalho e os conflitos de natureza econômica entre empregadores e trabalhadores de modo a incentivar a autocomposição entre as partes.

Nesse documento é possível observar os pilares dos Programas de Geração de Emprego e Renda, com forte estímulo ao trabalho atípico com apelo aos temas de desenvolvimento social e sustentável. O governo do presidente Luís Inácio Lula da Silva (2002-2009) segue o receituário do Pós-Consenso de Washington, pois conjuga medidas de cunho social-liberal, sem romper com as estruturas neoliberais, ao contrário, se rende às estratégias de valorização do capital, apoiando um conjunto de medidas para favorecer e proteger o investimento das transnacionais, em detrimento dos investimentos em Educação, Saúde, Habitação, entre outros.

3 Força-tarefa instituída pelo presidente Fernando Henrique Cardoso, no início de 1998, objetivando medidas de geração de emprego e renda. 
O governo do presidente Luís Inácio Lula da Silva e a continuação deste, com a Presidente Dilma Roussef (2010- 2014), apresentam "uma mescla sui generis entre medidas do social-liberalismo e do novo-desenvolvimentismo" (CASTELO, 2010: 23), pois se orientam pelos temas neoestruturalistas (redução da heterogeneidade produtiva e social, progresso técnico e inovação). Da mesma forma se orientam pela teoria do comércio internacional que enfatiza "o crescimento endógeno cujo fator essencial é o progresso técnico e tem como instrumento a abertura dos mercados e a liberalização" (SALUDJIAN, 2010: 149).

É sob esta ótica que os governos neodesenvolvimentistas passaram a enfatizar as políticas sociais de caráter assistencialista e focalizada de transferência de renda, como Bolsa Escola, Bolsa Alimentação, Vale Gás e Comunidade Solidária no governo de FHC e os programas Bolsa Família, Erradicação do Trabalho Infantil (PETI), Minha Casa, Minha Vida, Programa Nacional de Apoio à Agricultura Familiar (PRONAF), Luz para Todos, Economia Solidária, Universidade para Todos (PROUNI) e o Pacto de Aceleração de Crescimento (PAC) nos governos de Lula da Silva e Dilma Roussef.

Nesse contexto, a política de trabalho, emprego e renda na última década foi voltada para garantir a legalidade das práticas decorrentes da flexibilização das relações do trabalho, principalmente, nos Programas de Geração de Emprego e Renda financiados pelo Fundo de Amparo ao Trabalhador/FAT, de estímulo ao autoemprego, do aumento das capacidades individuais e desenvolvimento econômico, identificando-se com as recomendações do Banco Mundial e com outras iniciativas internacionais.

Além desses programas, destacam-se também os financiamentos no âmbito do Programa Nacional de Microcrédito Produtivo Orientado (PNMPO), o financiamento de Projetos de Infraestrutura no País e o Programa de Modernização do Parque Industrial Nacional - Moderna (que objetiva promover a modernização da indústria e a dinamização do setor de bens de capital no país). Nesta perspectiva, ao trabalhador é repassado o ônus de se tornar "empregável" e atender as exigências de competitividade e produtividade do mercado de trabalho. Com efeito, os governos neodesenvolvimentistas apostam no financiamento de programas que visem à qualificação profissional do trabalhador como requisito de colocação e recolocação ao mercado de trabalho.

Assim, o Brasil vem se destacando nos acordos de integração regional, principalmente no que se refere aos investimentos em programas de infraestrutura. Um bom exemplo destes investimentos é o Programa de Aceleração do Crescimento (PAC), o qual prevê investimentos em rede de transporte, objetivando facilitar o escoamento da produção, o incremento no sistema de 
telecomunicações na perspectiva da garantia de uma moderna e ágil comunicação entre as grandes corporações e ainda um incremento no abastecimento de energia através do reinvestimento na construção de hidrelétricas. Constata-se, então, que o chamado neodesenvolvimentismo se aproxima do modelo de crescimento orientado para fora, que foi defendido pelo Banco Mundial nos anos 1980. Isto é, trata-se de um modelo de crescimento baseado na exportação combinado com um mercado interno forte, no qual o Estado cria oportunidades de investimento sob o argumento de que o crescimento das exportações possibilitará o aumento da renda com impacto nas desigualdades sociais (GONÇALVES, 2012).

Carcanholo (2010) chama essa perspectiva da Nova CEPAL de "revisionista", pautada na ideia de "reformas das reformas":

Em suma, a nova proposta cepalina não é de reversão das reformas, mas de gerenciamento e direcionamento dos efeitos da abertura comercial e da liberalização financeira externa, de forma a canalizar o capital externo para atividades produtivas voltadas preferencialmente para exportações, ao mesmo tempo, que se procura a equidade social, embora as políticas para tanto sejam muito mais de caráter compensatório do que a reversão de estratégia de desenvolvimento propriamente dita. A agenda cepalina de 'reformas das reformas' parece significar muito mais um gerenciamento das 'imperfeições' das reformas neoliberais do que uma concepção significativamente distinta de desenvolvimento (CARCANHOLO, 2010: 138).

Essa afirmação se pauta no fato de não haver mudança no sentido que orienta o padrão de regulação econômica e social do capitalismo nessa fase de mundialização do capital, que tem como base a financeirização da economia e a acumulação flexível.

\section{DESENVOLVIMENTO E NEODESENVOLVIMENTISMO NA AMAZÔNIA BRASILEIRA: A SINGULARIDADE DO ESTADO DO PARÁ}

A ditadura militar que marcou o Brasil no período de 1964 -1985 empreendeu uma de suas mais importantes tarefas - a ocupação da Amazônia -, criando-se a falsa ideia de que a Região seria uma terra sem homens, daí porque o slogan do governo da época, terra sem homens, para homens sem terra. Estes homens sem terra eram aqueles desalojados do campo pela expansão do capital no Centro-Sul e Sudeste cuja migração para as cidades poderia representar um foco potencial de problemas sociais. Com essa estratégia de abertura das fontes de recursos naturais à exploração capitalista, de vital importância para a nova etapa da acumulação iniciada após a Segunda Guerra Mundial, teve início o verdadeiro processo que culminou com a ocupação desordenada e predatória da Amazônia. 
A construção de estradas na Amazônia, na década de 1970, se inscreve no conjunto de medidas adotadas pelos governos militares para a região, destacando-se também a implantação de empreendimentos diversos e ainda os programas de colonização associados à construção da Transamazônica (1972) . Todas essas ações promovem a abertura da Amazônia ao capital internacional, especialmente pela via privilegiada da exploração de seus recursos minerais, o que já fora iniciado desde a década de 1950 com a extração de manganês no estado do Amapá. Seguiram-se a extração de celulose pelo projeto JARI; a exploração de bauxita pela Companhia Vale do Rio Doce; a exploração de minério de ferro pelo Programa Grande Carajás, compreendendo o complexo mina-ferrovia-porto e a produção de alumina e alumínio pelo Projeto Albras-Alunorte, em Vila do Conde (Murucupi), distrito de Barcarena, no estado do Pará.

$\mathrm{Na}$ década de 1980, além dos projetos econômicos de mineração implantados, foram também instalados projetos de infraestrutura em alguns estados da Amazônia brasileira, como a construção da hidrelétrica de Tucuruí, no estado do Pará, e a hidrelétrica de Balbina, no estado de Rondônia. Todos esses empreendimentos produziram elevadas taxas de acumulação de capital e crescimento econômico para o mercado extrarregional: nacional e internacional.

Segundo Hébette, um dos intelectuais amazônidas pioneiros na crítica ao que ele denomina "mito de uma concepção de desenvolvimento regional",

O grande capital, estatal e privado do ramo do ferro, da bauxita, do alumínio, da energia elétrica, tornou-se rei e lei: com toda a sua soberba, remodelou o espaço, abrindo nele, de sul a norte, de oeste a leste, minas, represa de rio e lago artificial, linhas de alta tensão, ferrovia, lagoas de resíduos minerais, sem consideração nem pelas populações locais, tanto tradicionais como os recentemente imigrados. As grandes empresas de pesca e de madeira, modernamente equipadas, ávidas pelo lucro (HÉBETTE, 2004: 23) ${ }^{5}$

O ideário neodesenvolvimentista difundido no Brasil, principalmente, nas primeiras décadas dos anos 2000 não alterou o lugar da Amazônia na divisão internacional e nacional da exploração do trabalho. No caso específico do Pará ${ }^{6}$, espaço por excelência de commodities na região, amplia-se o investimento

\footnotetext{
A rodovia Transamazônica é a terceira maior rodovia do Brasil, com $4.223 \mathrm{~km}$ de comprimento, atravessando sete estados brasileiros: Amazonas, Pará, Tocantins, Maranhão, Piauí, Ceará e Paraíba.

5 Grifos nossos.

6 O estado do Pará, localizado na região Norte do Brasil, é a segunda maior unidade federativa do país em termos territoriais. Em 2013, segundo o IBGE, sua população era de 7.969.654 habitantes (388.603 pessoas a mais que os dados recolhidos pelo Censo Demográfico de 2010). O Pará possui 144 municípios distribuídos em um território de $1.247 .954 .666 \mathrm{~km}^{2}$. Sua capital, Belém, situada no nordeste do estado, apresentava no mesmo ano uma população estimada em 1.425.922 habitantes e um território de $1.059 .406 \mathrm{~km}^{2}$.
} 
no setor industrial iniciado desde os anos 1980, que tem como carros-chefe as megaindústrias do setor minerometalúrgico, sendo o maior complexo da América Latina no beneficiamento de alumina e produção de alumínio. Este setor se expressa por meio das empresas Alunorte e Albrás/Hydro em Barcarena ${ }^{7}$ e a Companhia Vale do Rio Doce, hoje, apenas Vale ${ }^{8}$ - esta última considerada a maior multinacional do Brasil e uma das maiores do mundo, devido à qualidade do minério de ferro extraído de Carajás ${ }^{9}$, em Parauapebas ${ }^{10}$. Ademais, multiplicamse os investimentos em hidrelétricas.

Para dar suporte aos grandes projetos de mineração implantados ou por implantar no estado do Pará, atualmente estão em construção três hidrelétricas, com destaque para a maior - a hidrelétrica de Belo Monte ${ }^{11}$, no rio Xingu, sudeste paraense, que atinge um número significativo de territórios indígenas e ribeirinhos. A operação de Belo Monte tem implicado a desterritorialização de povos indígenas e camponeses por meio de expropriação e violação das diversas formas de direitos, particularmente o direito ambiental com a contaminação dos rios, alterando o ecossistema da região e, por conseguinte, modus operandi das populações tradicionais.

Os impactos negativos do projeto energético expresso pela construção da hidrelétrica de Belo Monte se traduzem também em rápido crescimento da

O município de Barcarena está localizado a 40 quilômetros da capital, Belém. Este município pertence à microrregião de Belém, tem uma área de 1.310,33 $\mathrm{km}^{2}$, com aproximadamente 99.859 habitantes (IBGE, 2010), das quais 49.513 são mulheres. Segundo dados do último censo (2000), 30\% da população ocupada era composta de trabalhadores (as) por conta própria. Segundo dados da Fundação de Amparo a Pesquisa do Pará (FAPESPA), em 2015, Barcarena ocupou o terceiro lugar na geração do Valor Adicionado ao Produto Interno Bruto/ PIB do estado do Pará.

8 A empresa Vale S.A. foi fundada como estatal no ano de 1945, em Itabira, Minas Gerais, pelo então presidente Getúlio Vargas. Denominada Companhia Vale do Rio Doce - CVRD, foi criada para suprir a demanda por ferro no Brasil e nos países que estavam em reconstrução no pós-guerra. Foi privatizada em 1997, como parte integrante do pacote de reformas neoliberais implementadas no governo FHC e, atualmente, é uma empresa transnacional de capital aberto, monopólio no ramo de mineração, com sede no Brasil e atividades em cerca de trinta países. Segundo dados da Fundação de Amparo a Pesquisa do Pará (FAPESPA), em 2015, Parauapebas - município onde se realiza a extração de minério de ferro pela VALE -se constitui, depois de Belém, como o município de maior geração do Valor Adicionado no PIB do estado do Pará $(18,39 \%)$.

9 A região de Carajás está localizada na mesorregião Sudeste do Pará e compreende os municípios de Parauapebas, Canaã dos Carajás, Eldorado dos Carajás e Curionópolis.

10 O município de Parauapebas está localizado a $645 \mathrm{~km}$ da capital Belém, foi criado em 1988 como decorrência de seu desmembramento do município de Marabá. Este município está localizado no sudoeste do estado. Cresceu em virtude ao intenso fluxo migratório provocado pela instalação de grandes projetos para a extração de recursos naturais, tais como o Projeto Grande Carajás, conduzido pela então Companhia Vale do Rio Doce (hoje Vale) e da enorme quantidade de ouro extraído da Serra Pelada. Em relação aos dados referentes à população, área territorial e densidade demográfica, no ano de 2010, apresentava 153.908 habitantes, 6.957 $\mathrm{Km} 2$ e 22,12hab/km2 (IBGE, 2010). 
oferta da força de trabalho. Os operários oriundos de vários estados do Brasil passam a ser alvo de brutal superexploração ${ }^{12}$, motivada por uma força de trabalho redundante, que se submete a baixos salários, prolongamento da jornada e intensificação do ritmo do trabalho, culminando não apenas em acidentes de trabalho, como também em formas de adoecimento físico e mental.

Essa realidade social tem sido alvo de sedições e conflitos entre lideranças indígenas e quilombolas, bem como entre operários e representantes do governo, da Norte Energia (empresa responsável pelo empreendimento), contidas pelas forças da ordem e da lei. Ademais, as cidades localizadas no entorno, particularmente Altamira, considerada polo principal da região, tem sido alvo de denúncias concernentes à migração exacerbada que provoca desequilíbrio entre oferta de serviços sociais e crescimento urbano, impulsionando os preços de alimentos, aluguel etc. Estudos de campo realizados nos espaços socioasssistenciais, responsáveis pela execução das políticas de assistência social nos municípios que sediam as empresas multinacionais de mineração e energéticas no Pará, indicam o aumento da violação de direitos de mulheres e crianças, reverberado pela prostituição, abuso sexual de crianças e adolescentes, homicídios, femicídios, desemprego, subemprego, alcoolismo etc. Desse modo, observa-se a manutenção do lugar histórico que os trabalhadores mais desprotegidos têm ocupado nesses empreendimentos que reeditam os discursos correntes sobre neodesenvolvimentismo como falácia para o social.

Da mesma forma pesquisas (Nascimento, 2009; Gomes et al., 2012) sobre as formas de trabalho existentes no estado do Pará demonstram que, ao se comparar com a situação nacional, não têm mudado o perfil socioeconômico dos trabalhadores. Os setores mais dinâmicos do ponto de vista do mercado de trabalho formal e, portanto, da expansão do emprego, têm sido o da construção civil, indústria madeireira, mineração, siderurgia e garimpo. O emprego formal

12 Segundo Marini (2000) apud Amaral et al. (2012), as perdas de mais-valia que as burguesias latino-americanas sofrem com o intercâmbio desigual levam-nas a "agudizar os métodos de extração do trabalho excedente", ou seja, a superexploração do trabalho. Esta se dá em função dos mecanismos de transferência de valor entre as economias periféricas e central, levando a mais-valia produzida na periferia a ser apropriada e acumulada no centro, guardando relação evidente com a lei geral da acumulação capitalista. Trata-se, então, de um capitalismo sui generis na periferia, justamente porque parte do excedente gerado nesses países é enviada para o centro na forma de lucros, juros, patentes, royalites, deterioração dos termos de troca, entre outros, não sendo, portanto, realizada internamente. Assim, os mecanismos de transferência de valores provocam, digamos assim, uma interrupção da acumulação interna de capital nos países dependentes que precisa ser contemplada e, para tanto, mais excedente precisa ser gerado. Essa expropriação de valor só pode ser compensada e incrementada no próprio plano da produção - justamente - através da superexploração (arrocho salarial, extensão da jornada de trabalho em associação com a intensificação do trabalho), e não no nível das relações de mercado, por meio de desenvolvimento da capacidade produtiva. 
é bastante reduzido com baixa qualificação nas empresas subcontratadas pelas multinacionais. Segundo o Mapa da Exclusão Social do Pará, elaborado pelo Instituto de Desenvolvimento Econômico, Social e Ambiental do Pará (IDESP), que reúne indicadores representativos das condições de vida da população paraense, no ano de 2010, apesar de o

Estado ter alcançado a $8 .^{\mathrm{a}}$ posição no ranking nacional de taxas de incremento, o coeficiente de Gini indica uma elevação no grau de concentração de renda, resultando no aumento da população considerada abaixo da linha da pobreza, de 10,88\%, o que equivale a mais de $237 \mathrm{mil}$ pobres em 2009, em relação ao ano de 2008 (IDESP, 2011: 23).

Entre os vários impactos sociais decorrentes do modelo de desenvolvimento implementado na Amazônia, em especial no estado do Pará, destacam-se ainda as mortes causadas por conflitos pela posse da terra. O Relatório da Comissão Pastoral da Terra (CPT) apresenta um quadro das mortes de trabalhadores do campo brasileiro, principalmente no estado do Pará, no período de 1985 a 2010. Este relatório, encaminhado ao Ministério da Justiça, em 2010, registra que foram assassinadas 1.580 trabalhadores, em 1.186 ocorrências no Pará. Em face deste quadro, as lideranças dos referidos trabalhadores buscam a implementação de políticas públicas reais que respondam as demandas dos camponeses e das populações originárias que habitam neste complexo espaço agrário marcado, não raro, pelo discurso do desenvolvimento sustentável e ambiental.

As políticas públicas formuladas para atender as demandas do capital não surtem o mesmo efeito que as políticas sociais, fundiárias e agrárias dirigidas para a população local. Nas últimas décadas do século passado e início do século XXI, ainda se identifica o número crescente de assassinatos de trabalhadores rurais, lideranças de lutas sindicais e ambientalistas, circunscritas nos Programas de Assentamento Agroextrativistas (PAEs), dentro da institucionalidade. Merece destaque o caso do assassinato da missionária norte-americana irmã Doroty Stang, em 2005, e do casal Maria do Espírito Santo da Silva e José Cláudio Ribeiro da Silva, em maio de 2011, somente para citar os mais difundidos pela mídia nacional e internacional

Outra expressão da degradação das condições de vida e trabalho na região diz respeito à presença do denominado trabalho em condições análogas à escravidão. Em 2014, a Superintendência Regional de Trabalho e Emprego no Pará resgatou 121 trabalhadores nessas condições durante 32 operações em 18 municípios paraenses. Rondon do Pará foi o município com o maior número de resgates - 32, seguido de Xinguara, com 23, e Ulianópolis, com 14. Estes municípios localizam-se no sudeste do estado e juntamente com o sul do Pará 
concentram grande parte de atividades de trabalho na pecuária, atividade com maior incidência de ações de fiscalização e combate àquelas formas de trabalho. Outras atividades nas quais se apresentam situações análogas ao trabalho escravo são: construção civil, indústria madeireira, agricultura e carvoaria.

Os projetos econômicos minerometalúrgicos e energéticos que caracterizam o Pará, no presente, como polo neodesenvolvimentista estão conectados com o processo de reestruturação produtiva global que deslocou a produção de diversos setores para países "semi-industrializados", modificando a paisagem ambiental e social dos municípios onde se instalam. Dois dos municípios paraenses de maior impacto em relação a essas mudanças são Barcarena e Parauapebas. O resgate da trajetória de vida dos trabalhadores desses municípios indica que eles reproduzem a experiência dos homens sem terra desalojados nos anos 1960 e 1970. Sendo assim, a particularidade desses trabalhadores está no fato de que os migrantes, em sua maioria oriunda do nordeste brasileiro, principalmente do estado do Maranhão, geograficamente vizinho ao estado do Pará, continuam acreditando no discurso de que o desenvolvimento econômico proporcionado pelos empreendimentos contempla o social e, por conseguinte, possibilitará melhoria nas condições de vida. A esperança em melhores dias se faz presente, principalmente entre as mulheres, uma vez que a precarização do trabalho atinge de forma distinta os sexos.

Segundo Hirata (2006), o emprego feminino se configura em quase todos os países, como mais precário e instável em relação ao emprego masculino. Os empregos de meio período e tempo parcial são na sua maioria de responsabilidade das mulheres, assim como a atividade informal. Ainda segundo a autora "esses empregos femininos precários podem prefigurar o padrão de assalariamento do futuro para ambos os sexos" (HIRATA, 2006: 200). Ademais, prossegue a autora,

A globalização teve como conseqüência, desde os anos noventa, a elevação dos níveis de emprego das mulheres, mas, ao mesmo tempo, acelerou o processo de vulnerabilidade e precarização desses empregos. A esse paradoxo, responde um segundo, o da dispersão e atomização das mulheres, dadas as mudanças nas modalidades de emprego (trabalho a domicílio, teletrabalho, formas ditas 'atípicas' de emprego, etc.) (HIRATA, 2006: 202).

Assim, analisando os dados sobre a inserção da mulher no mercado de trabalho formal, particularmente nas empresas multinacionais instaladas em Barcarena e Parauabepas, observa-se que uma parcela minoritária das trabalhadoras contratadas está vinculada às atividades do setor de recursos humanos em funções administrativas como secretárias. A maioria das trabalhadoras são 
mulheres vinculadas às cooperativas de serviços, terceirizadas pelas empresas que se encarregam das funções de limpeza de ambientes e lavagem dos uniformes dos trabalhadores que exercem atividades mais qualificadas nas mencionadas empresas. A remuneração dessas mulheres gira em torno da metade do salário mínimo brasileiro, que hoje é de $\mathrm{R} \$ 724,00$.

A exemplo da realidade nacional, o desemprego e o subemprego de mulheres e jovens nos referidos municípios têm sido enfrentados por meio das Políticas de Qualificação, Emprego e Renda, uma vez que para o discurso empresarial e governamental o desemprego é uma questão de competência individual. Neste sentido, trabalhadores/as subempregados e desempregados investem nos cursos gratuitos de qualificação em que pese a sua reduzida efetividade. O Programa Nacional de Acesso ao Ensino Técnico e Emprego (PRONATEC) ilustra bem a situação.

Considerado como um dos principais programas do Brasil para o enfrentamento das condições de inserção produtiva dos trabalhadores brasileiros mais empobrecidos, apesar de bastante difundido, não tem garantido a absorção pelo mercado de trabalho dos seus egressos. A qualificação ofertada ocorre sob o paradigma da precarização, ou seja, cursos que aperfeiçoam habilidades que o trabalhador possui e com pouco valor agregado pelas empresas. Segundo Sales (2015), mesmo os trabalhadores jovens qualificados pelo programa de qualificação da multinacional Vale são poucos absorvidos por ela, evidenciando as contradições do discurso neodesenvolvimentista de que a capacitação da força de trabalho possibilita o combate ao desemprego.

\section{CONSIDERAÇÕES FINAIS}

A reflexão desenvolvida neste texto por meio do resgate de contribuições teóricas sobre o tema do desenvolvimentismo sugere que a institucionalização e instrumentalização do desenvolvimento como centralidade pragmática pelo campo hegemônico capitalista tende a dispersar e diluir a potencialidade do discurso crítico que concebe o desenvolvimento no contexto do projeto de emancipação humana como totalidade que une homem e natureza em direção à humanidade histórica, e não à barbárie.

O resgate dos processos históricos de exploração capitalista na particularidade Amazônica brasileira não deixa dúvida acerca dos resultados do modelo de desenvolvimento adotado para a região: acumulação de capital e a concomitantemente pauperização dos trabalhadores. A destruição da natureza, a mercantilização dos recursos naturais e minerais, a expulsão dos povos originários 
de suas propriedades e a degradação dos que permanecem vivos na resistência são expressões de denúncia da "ineficiência" do Estado em fazer cumprir as leis que reivindicam desenvolvimento econômico com responsabilidade social e ambiental.

A pauperização na Amazônia rural e urbana e os assassinatos de lideranças no campo, lócus dos produtos transformados em commodities, interrogam os críticos da concepção de desenvolvimento, até hoje predominante, sobre os conceitos que fundam a interpretação dos conflitos na região e permeiam as políticas públicas em geral e as de trabalho, emprego e renda, em particular.

\section{REFERÊNCIAS}

AMARAL, M. S. e CARCANHOLO, M. D. Superexploração da Força de Trabalho e Transferência de Valor: fundamentos da reprodução do capitalismo dependente. In: FERREIRA, C.; OSÓRIO, J.; LUCE, M. (Org.). Padrão da Reprodução do Capital. São Paulo. Boitempo, 2012, p. 142.

BOSCHETTI, I. América latina, Politica Social e Pobreza: "novo modelo de desenvolvimento". In: SALVADOR, Evilásio; BEHRING, E. et al (orgs.). Financerização, Fundo Público e Política Social. São Paulo: Cortez, 2012.

CARCANHOLO, M. Neoconservadorismo como roupagem alternativa: a nova Cepal dentro do consenso de Washington. In: CASTELO, R. (org.). Encruzilhadas na América Latina no Século XXI. Rio de Janeiro: Pão e Rosas, 2010. p. 119-141.

CASTELO, R. O novo desenvolvimentismo e a decadência ideológica do estruturalismo Latino-Americano. In: CASTELO, R. (org.). Encruzilhadas na América Latina no Século XXI. Rio de Janeiro: Pão e Rosas, 2010. p. 191-211.

O novo desenvolvimentismo e a decadência do pensamento econômico brasileiro. Revista Serviço Social \& Sociedade, n. 112, São Paulo, out./dez., 2012. p. 613-636.

FIORI, J, L. Não há vitória do keynesianismo nem abandono da ideologia liberal. Jornal folha de São Paulo. São Paulo 03/05/2009, 2009. p. 01-02.

GOMES, V. L. B. O; et al. (Orgs). O Avesso dos direitos: Amazônia e Nordeste em questão. Recife, Editora Universitária/ UFPE, 2012.

GOMES, V. L. B., CASTRO, E. M. R. - Trabalhadores da Albras e sua organização política. Belém, Novos Cadernos NAEA. NAEA/UFPA. Vol. 7, n. 1. p. 123154, jul-dez 2004 
GONÇALVES, R. Redução da desigualdade da renda no governo Lula: análise comparativa. In: SALVADOR, E.; BEHRING, E. et al (orgs.). Financerização, Fundo Público e Política Social. São Paulo: Cortez, 2012.

HÉBETTTE, J. Migração, colonização e ilusões do desenvolvimento. In: HÉBETTE, J. Cruzando Fronteiras: 30 anos de estudos do campesinato na Amazônia, V. I, Belém, Edufpa, 2004. p. 373.

HIRATA, H. Interview: Helena Hirata, Revista Trabalho, Educação e Saúde. V. 4, N. 1, Rio de Janeiro, 2006. p.199-203.

IBGE - INSTITUTO BRASILEIRO DE GEOGRAFIA E ESTATÍSTICA. Censo 2010. Disponível em < http:/ / www.ibge.gov.br>. Acesso em: 17 mai. 2015. IDESP - INSTITUTO DE DESENVOLVIMENTO ECONÔMICO, SOCIAL E AMBIENTAL DO PARÁ. Mapa de Exclusão Social do Pará 2010. Pará, Idesp, 2011.

MARINI, R. M. Dialética da Dependência. Petrópolis: Vozes, 2000.

NASCIMENTO, M. A. C. O paradoxal desenvolvimento do Estado do Pará: Efeitos no social. In: SCHERER, E. (Orgs.). Questão Social na Amazônia, Manaus, Editora da UEA,2009. p. 39-64.

POLANYI, K. A Grande Transformação: as origens de nossa época. Rio de Janeiro, Editora Campus Ltda, 1980.

RELATÓRIO CNETD.pdf. http://acesso.mte.gov.br/data/files/8A7C812 D41032A78014118FD3C857B5A. Acesso: novembro, 2015.

SALES, C. R. L. Desemprego e Qualificação Profissional em Parauabepas no Estado do Pará. Dissertação (Mestrado em Serviço Social - Programa de Pós-Graduação em Serviço Social, Universidade Federal do Pará) 167 f. Belém, UFPA, 2015.

SALUDJIAN, A. (2010), "Estratégias de desenvolvimento e inserção da América Latina na economia mundial, os estruturalistas e neoestruturalistas da CEPAL: uma abordagem crítica", In: CASTELO, R. (org.). Encruzilhadas da América Latina no século XXI. Rio de Janeiro: Pão e rosas, 2010. Disponível em < http://www. sindusconpa.org.br/detalha_noticia.php?id=4708>. Acesso em: 4 jun. 2007.

SAMPAIO JR., P. A. Desenvolvimentismo e Neodesenvolvimentismo: tragédia e farsa. Revista Serviço Social \& Sociedade. n.112, São Paulo, out./dez, 2012. p. 672-688.

WILLIAMSON, J., KUCZYNSKI, P. Depois do Consenso de Washington: retomando o crescimento e a reforma na América Latina. São Paulo, Saraiva, 2014. 